\title{
Mapping the Future of Research in Web-Based Education Management
}

\author{
Effective HCI Taken to New Horizons
}

\author{
Elspeth McKay, Brian Garner, Toshio Okamoto \\ RMIT University, School of Business Information Technology, School of Engineering \& IT, \\ Deakin University, University of Electro-Communications, Tokyo, Japan
}

Abstract: The educational research community attracts practitioners and policy makers interested in both consuming and producing high quality educational research methodologies. Over time, research findings significantly contribute to continuing educational theory as well as educational management and professional practice. Until now researchers have been able to understand the interactivity of instructional strategies and cognitive performance in traditional learning models. While the community has been exposed to these findings through professional publications and the electronic media; with the advent of Web-based educational research, the same cannot be said about dissemination from this emerging techno-educational paradigm. Is this due to the complex nature of the contributing factors involved with educational management that involves information and communications technologies (ICT) in the Webmediated learning environments? In terms of the relationship between information technology and education management, defining such educational research is becoming quite difficult. This paper analyses research by practitioners primarily interested in Web-based education. To examine the trends, contributions are examined from a wide range of educational researchers at a recent international conference that attracted participants from 29 countries. These trends will be extrapolated to map the future of Webbased education management based on international synergies in research communities of practice.

Keywords: Web-based, Web-mediated, information and communications technology, human-computer interaction, context-awareness, learning reinforcement, flow experience, podcasting.

\section{BACKGROUND}

Each year there are a number of international conferences that concentrate on educational research; none are actually convened to examine

Please use the following format when citing this chapter:

McKay, E., Garner, B. and Okamoto, T., 2007, in IFIP International Federation for Information Processing, Volume 230, Knowledge Management for Educational Innovation, eds. Tatnall, A., Okamoto, T., Visscher, A, (Boston: Springer), pp. $159-166$. 
education management. To this end, this paper reports on one such event, which took place in Melbourne, Australia, during November 2004; the International Conference on Computers in Education (ICCE2004-FullProceedings 2004). A unique feature of this conference was its concentration on high-quality research dedicated to educational technology in the AsiaPacific region. Overall, this event attracted 350 registrations from 29 countries, with a total of 252 papers that were presented in the 3-day scholarly programme. This paper aims to provide a critical analysis of the scholarly discourse emanating from the papers that were submitted to this international conference. Leaving aside the notions of education management, the diversity of the educational technology community is shown first, followed by an analysis of the evidence from this forum on Web-based educational research, which suggests the future direction of research in Web-based education.

\section{CROSS CULTURAL DEMOGRAPHICS}

Overall there were 340 submissions representing a truly global knowledge exchange. Papers were submitted to a double blind peer review process. Where there were inevitable instances of disagreement and/or clash of review outcome, those papers in dispute were then submitted to a third independent review. Through this rigorous blind review, only the best quality papers were chosen as long papers. Examination of the Conference Proceedings reveals that the Reviewer Listing totals over 70 international reviewers. Finding suitable academic reviewers for a conference of this size would present a daunting task for any conference organizing committee. Figure 1 depicts the authorship demographics showing the global nature of the participation from the Asia-Pacific region and the wider community of educational technologists.

\section{WEB-MEDIATED EDUCATION MANAGEMENT}

\subsection{Adaptive online tutoring and intelligent learning tools, and virtual reality}

There were 42 papers that dealt with advanced HCI to deliver computergenerated intelligence. An examination of the authors' affiliation reveals unilateral research team membership where there may be little opportunity to collaborate across multidisciplinary fields. Perhaps this is not so surprising, according to Preece (1994) the major contributions to HCI have come from the more traditional fields of computer science, cognitive psychology, social and organizational psychology, and ergonomics and human factors. However it is interesting to note that it is the virtual reality 
research projects presented in these conference proceedings that combine multi-skilled teams, to produce an interesting synthesis of professional practice. Whereas the adaptive online tutoring projects, do not. Instead they have a strengthened focus on the technological development per se. While these latter mentioned research teams are succeeding with their projects, they must remain cognizant of the danger of not considering the humandimension of their HCI. This means keeping one eye on the technology of their system building, while at the same time making sure that they are mindful of how this system fits in with what people are doing with this system (Peece, 1994).

\section{Conference Submissions - Total 340}

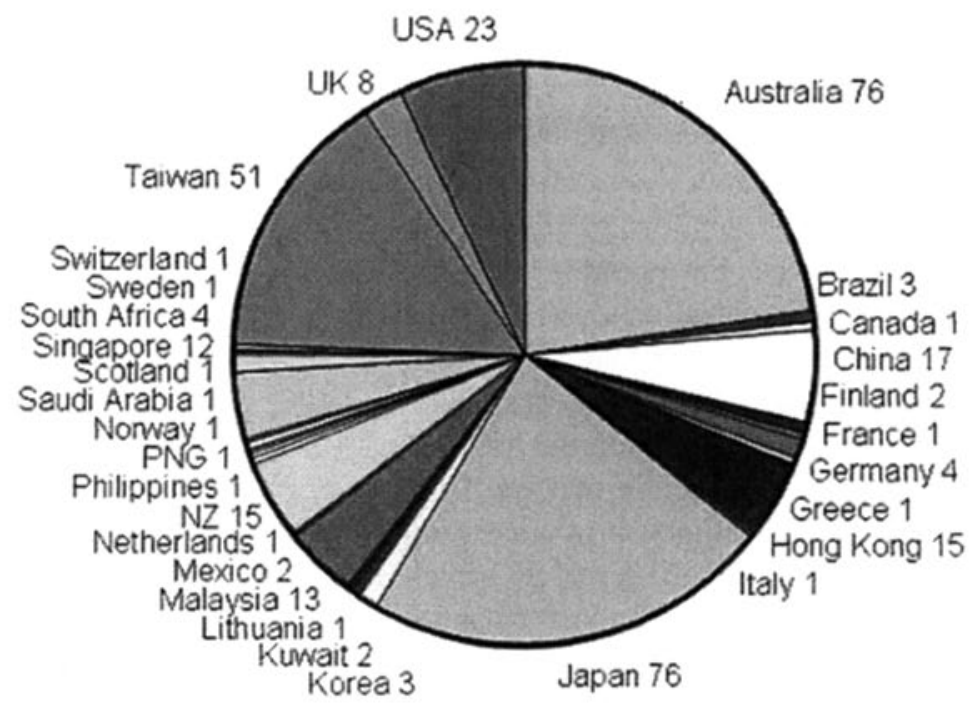

Figure 1 : Conference Submission Demographics

\subsection{Collaborative knowledge sharing, teacher education, language learning, and assessment techniques}

There were 78 papers in this group that focussed on knowledge acquisition. They represent the largest number of projects that implement ICT in a Web-based environment. Multi-disciplinary collaboration is strongest amongst the education and information technologists. However, notable amongst this contribution to education management and information technology research is the paper on context-awareness $(\mathrm{Li}$, Zheng, Ogata and Yano 2004). While Li et al (2004) concentrate on the portability of learning environments and do not refer directly to the practice of Web-based instruction; there is a clear message on (education) knowledge management for researchers to learn from here. That is, the requirement for researchers to consider the social nature of learning. This important inter-relationship 
between tacit and explicit knowledge is captured by these researchers with their five-dimensional representation for context-awareness.

The problem of knowledge retrieval permeates through many of these papers. The advent of multimedia means our propensity to become knowledge squirrels is realized. Visual image storage has brought forward this dilemma. This is a problem that is growing rapidly due to the increase in the range of affordable digital technological devices and the ease in which the information/knowledge is captured as textual/visual objects. There are many untapped educational resources that can enhance a student's understanding. To this end, high quality database management repositories are critical. As far as education management is concerned, research from the industry sector is showing that attention must turn from the concentrated textual retrieval to the requirement for retrieving stored images from the www. Otherwise the podcasting phenomenon will pass education sector by.

\subsection{Wireless environments (cellular phones and PDA devices)}

While there are only 14 papers that focus on portable devices, nonetheless they offer a powerful reminder to this educational forum of the things to come. Therefore, it comes as no surprise to see this novel work positioned within the community of distance education researchers. Podcasting is a prime example of the emerging technologies on the horizon. There were five projects that involve cellular phones, while two use PDA devices and two devote their paper to wireless connectivity. It is interesting to note here that the only other scholarly stream of research which acknowledges wireless connectivity as a serious education management resource is found amongst the evaluation and learning technologies proponents. In the distance education group there were five papers from Japan, and two from Taiwan that focus on the technology-dimension of these mobile devices. However, it is in the contributions from Australia and the UK where the human-dimension is identified strongly.

\section{SUMMARY OF VIEWS}

Seven conference sub-themes covered a wide variety of scholarly ePedagogy innovating effective human-computer interaction ( $\mathrm{HCl}$-through ICT. Papers examined showed evidence of an explicit relationship with Web-based learning, while others showed a more implicit connection to a Web-mediated educational context. Four categories of research were identified: differentiation capability for HCI, knowledge management, transportable environments, and design. In the first category, the majority of the work fell amongst the $\mathrm{AI} /$ networked learning and the evaluation community. The papers that were strongly aligned to knowledge management attracted a broader coverage; these papers surfaced through the 
distance learning, eLearning, and Web-mediated learning tool conference stream/topics. While papers on transportable educational devices were aligned to distance education, they were the smallest concentration of Webbased research. Finally, there were 38 authors who displayed a connection to the process of design for Web-based learning; these papers were represented in the widest range of conference topics.

Differentiation capability for HCI: The highest proportion of papers for this group are to be found in the online tutoring, multi-agent social learning simulations, and assessment techniques. The work in this category concentrates on the human-machine dimension of HCI. Many of these papers describe a type of computer-generated intelligence that is generated by their learning environments. Understandably, these adaptive systems require the expertise from computer science or electronic engineering to predict the behaviour of the ICTs. Techno-knowledge about software design and development is critical with these projects. Meanwhile, excitement surrounding the virtual reality world brings about new synergies between the cognitive scientists who are primarily interested in the human-dimension of $\mathrm{HCI}$ and the machinery experts. This emerging field interested in various types of Web-based educational virtual worlds can be found in four of the seven conference themes. These papers all have the common characteristics of virtual reality because they allow the participant's senses to seemingly interact with the system. In virtual reality these systems should provide the participant with a sense of direct physical presence, some type of sensory cue in 3D (sight, sound or touch), and a natural feeling of interaction (Preece, 1994). However, it is the papers emanating from the conference themes of Evaluating Teaching and Learning Technologies that the humandimension of HCI leads the way forward. As such, these papers concentrate on the cognitive aspects of Web-based teacher educational platforms to deliver learning/instructional systems for reading and language learning.

Knowledge management: By far the heaviest concentration on Webbased knowledge management is found in the conference themes of Distance Education, eLearning and Knowledge Management, and Web-Mediated Learning Tools; while, there are a small number of papers in the AI and Evaluating Teaching and Learning Technologies conference sub-topics. However, this is the body of research that serves as the vital link between the realms of human-machine fit and adaptation, human-dimension, and the development process for Web-based interaction. Moreover, this is where the three important elements of learning are implemented; they include: the skills that are needed for task-related activities that are necessary for humans to perform at basic levels, knowledge acquisition we need to provide a deeper understanding of underlying concepts, purpose and functionality with the whole system in both the operation and conceptual level, and attitude development which underpins effective skill management (Smith, 1997); (Gagne, 1985).

Transportable environments: Analyzing the scholarly activity in educational technology research has revealed the emerging interest in 
wireless technologies. At this point, within the ICCE community, the contributions appear to be only tinkering with such devices. This is where a fresh approach to Web-mediated learning is initiated with communications engineering expertise. These transportable environments appear to offer major advancement in educational technology for the future. However, more research is required from the educational technology community before the effectiveness of these ICT tools is known. It also important to note that we must learn from the past, and ensure there is multi-disciplinary collaboration. Otherwise the negative effects of the so-called digital divide will restrict these innovations.

The danger for these transportable environments within the education/training sectors lies in our lack of understanding how to overcome the tendency to work at an ever increasing pace. Flicker (2002) describes four rules to overcome this tendency; they apply to educational technologists as much as they do to the corporate sector. These rules are to; avoid confusion by adopting inclusive design strategies, make a decided shift from racing to pacing, work within people's natural zone or flow state, and fulfill both people and the expected project outcomes. The concept of flow experience was introduced in 1975 by Csikszentmihalyi from the school of positive psychology; it is intimately related to intrinsic motivation. More recently flow experience has been measured by Smyslova \& Voiskounsky (2005). The major factors that contribute to flow experience are: there must be a good match between the user's needs and skills, and the inner structure of the programming tools, the quality of the live-help the system provides, and that manuals and text-books match the interests of every user. Moreover Smyslova \& Voiskounsky propose that the experiential tutorial should lose descriptiveness and contain actual projects that require an increasing degree of difficulty.

Design: The importance for high-quality software engineering emerges from the contributions at this conference. This emphasis recognizes that the greatest influence of Web-based learning environments is the creativity of the designer's skills for the interface mechanisms. Throughout the analysis of these conference papers we can see the combination of the engineering domain influencing the production of the educational artefacts.

As expected, the participation from such a broad spectrum of researchers provided rich insights into the cultural factors and Web-based pedagogical determination of e-Learning effectiveness. The more important conclusions reached by the authors are summarised below:

1. Web-based learning platforms must recognise the need for contextawareness, particularly in the education of student cohorts from diverse cultural backgrounds.

2. Knowledge retrieval effectiveness, and more generally, knowledge management, during student interaction is vital in terms of student satisfaction with the learning environment.

3. The establishment of common standards for student learning assessment is imperative as we move towards a global learning grid, involving 
credit transfer requirements and knowledge level certification. The growth of industry-based skill certification processes integrated with formal instructional models (didactic knowledge) needs recognition and endorsement, if changes in vocational requirements and blended learning practices are to be met.

4. The need for more effective mechanisms for transferring pedagogical practice and learning technologies between learning communities is now paramount, if the rich diversity of instructional design in Web-based learning environments is to be harnessed.

\section{FUTURE WEB-BASED EDUCATIONAL RESEARCH}

Future progress in Web-based instructional environments requires inspirational research, typically conducted within educational technology institutes, as discussed by Kunnath (2004). However, it is the requirement for life-long learning when competing in a global economic environment that has challenged many of the assumptions underpinning current educational practice.

Three new requirements may be identified:

1. Learning Reinforcement strategies are imperative, given current demographic trends in many countries, and the consequent need to reemploy older workers! In this context podcasting in its broadest sense is emerging as one of the brightest education management tools on the horizon. Although there may be a common perception this technique involves over-the-air broadcasting, podcasting lends itself in a natural sense towards education management. Many public domain Web sites are already springing up offering thousands of podcasts. The question will remain as to whether this type of education management environment can entice the practitioners to leave their more traditional class room management to reach towards audio and video feeds.

2. The cost to individuals of renewing skills and knowledge in a user-pays environment is forcing a critical appraisal of learning effectiveness. While Web-based learning environments are recognised as having a critical role to play in improving the cost-effectiveness of postgraduate training, the research challenge is to develop an appropriate methodology for operational audit of learning effectiveness.

3. The importance of the moving image is slowly being recognised in context-awareness processes, and while suitable technology platforms are still evolving, HCI using moving images can be expected to provide an important new horizon. 


\section{REFERENCES}

Csikszentmihalyi, M. (1975). Beyond Boredom and Anxiety: The Experience of Play in Work and Games. San Francisco, Jossey-Bass.

Flicker, B. (2002). Working at Warp Speed: The New Rules for Project Success in a Sped-up World. San Francisco, Berrett-Koehler.

Gagne, R. M. (1985). The Conditions of Learning: And the theory of instruction. NY, Holt/Rinehart/Winston.

ICCE2004-Full-Proceedings (2004), E. McKay, Ed. Acquiring and Constructing Knowledge Through Human-Computer Interaction: Creating new visions for the future of learning. International Conference on Computers in Education (ICCE2004), held in Melbourne, Australia - Nov 30 - Dec 3, Common Ground Publishing: ISBN 1863355731.

Li, L., Zheng, Y., Ogata. H. \& Yano, Y. (2005) Towards ubiquitous learning space, E. McKay, Ed. International Conference on Computers in Education (ICCE2004), held in Melbourne, Australia - Nov 30 - Dec 3, Common Ground Publishing: ISBN 186335573 $1,1315-1325$.

Preece, J. (1994). Human-Computer Interaction. Harlow - UK, Addison-Wesley.

Smith, A. (1997). Human Computer Factors: A Study of Users and Information Systems. Berkshire, McGraw-Hill.

Smyslova, O. V. \& Voiskounsky, A. E. (2005), The Importance of Intrinsic Motivation in Usability Testing. 3rd International Conference on Universal Access in HCI, held at the 11 th International Conference on HCI (AC, UAHCI, HIMI, OCSC, VR, U\&I, EPCE): Las Vegas, HCI-International.org. Full Proceedings on CD: ISBN: 0-8058-5807-5. Viewed on 15/01/05 at http://www.hci-international.org/. 